Hydrol. Earth Syst. Sci. Discuss., doi:10.5194/hess-2017-34, 2017

Manuscript under review for journal Hydrol. Earth Syst. Sci.

Discussion started: 13 February 2017

Hydrology and

\title{
Soil Moisture Estimation Based on Probabilistic Inversion over Heterogeneous Vegetated Fields Using Airborne PLMR Brightness Temperature
}

\author{
Chunfeng $\mathrm{Ma}^{1}$, Xin $\mathrm{Li}^{1 *}{ }^{1 * 2,3}$, Shuguo Wang ${ }^{4,1}$
}

\author{
*Corresponding author: Xin Li (lixin@1zb.ac.cn)
}

${ }^{1}$ Key Laboratory of Remote Sensing of Gansu Province, Northwest Institute of Eco-Environment and Resources, Heihe Remote Sensing Experimental Research Station, Chinese Academy of Sciences, Lanzhou, 730000, China

${ }^{2}$ CAS Center for Excellence in Tibetan Plateau Earth Sciences, Beijing, 100101, China

${ }^{3}$ University of Chinese Academy of Sciences, Beijing 100049, China

${ }^{4}$ Jiangsu Normal University, No. 101 Shanghai Road, Xuzhou, P. R. China

The L-band radiometer has demonstrated its strong ability of estimating soil moisture (SM) over vegetated surface. However, the present SM products derived from satellite radiometers are hardly directly used in heterogeneous oasis. This may be attributed to the coarse spatial resolution of the satellite-based observations and the defects of the point-estimation algorithms which cannot quantify the uncertainty in SM inversion. This paper presents a SM estimation based on the combination of Bayesian probabilistic inversion with high resolution airborne radiometer observations. The overall objective is to quantify the uncertainty in SM estimation and to provide a desirable SM estimation. Two retrieval strategies (2P and 3P strategy) are performed based on 6-channel Polarimetric L-band Multi-beam Radiometer (PLMR) observations collected during Heihe Watershed Allied Telemetry Experiment Research, and the ground measurements are used to validate the results. The main findings contain: 1) Accurate SM estimates with RMSE and ubRMSE less than $0.03 \mathrm{~m}^{3} / \mathrm{m}^{3}$, exceeding that of $0.04 \mathrm{~m}^{3} / \mathrm{m}^{3}$ of Soil Moisture Active and Passive (SMAP) and Soil Moisture Ocean Salinity (SMOS) missions target accuracies, are obtained. 2) The uncertainty in SM inversion is quantified with the value less than $0.095 \mathrm{~m}^{3} / \mathrm{m}^{3}$. 3) The Bayesian PI improves the simulation performance of forward model via maximum likelihood estimation. 4) The 3P and 2P strategies result in different SM inversion uncertainties. Overall, the present Bayesian PI combining multi-channel L-band observations has obtained a desirable SM estimation and uncertainty quantification, which may offer an insight into the future SM inversion based on passive microwave remote sensing.
\end{abstract}

\section{Abstract}


Hydrol. Earth Syst. Sci. Discuss., doi:10.5194/hess-2017-34, 2017

Hydrology and

Manuscript under review for journal Hydrol. Earth Syst. Sci.

Discussion started: 13 February 2017

Earth System

Sciences

(c) Author(s) 2017. CC-BY 3.0 License.

Discussions

\section{Introduction}

Soil moisture (SM) is a key variable in the process of water and energy balance at the land surface (Zhao et al., $\underline{2015}$; Kim et al., 2015). It usually presents strong spatial and temporal variation, resulting in difficulties of its analysis from in situ measurements, especially over large areas (Chaouch et al., 2013). Instead, it is promising that SM at large scale can be retrieved from passive microwave remote sensing observations (Martens et al., 2015; Calvet et al., 2011).

SM retrieval algorithm based on passive microwave remote sensing has been witnessed a huge development and refinement over the last several decades. Initially, the retrieval algorithms are mainly based on empirical methods (Shi et al., 2001), which are relative simple and easily to implement. However, due to the comprehensive understanding on complicity of microwave emission process and SM estimation, the algorithms are continuously refined and improved, and several complex and advanced algorithms were proposed, e.g., iterative (Njoku et al., $\underline{2003}$ ) and look up table algorithms (Koike et al., 2004) for Advanced Microwave Scanning Radiometer-Earth observation mission (AMSR-E), optimization of cost function (Wigneron et al., 2007) for Soil Moisture and Ocean Salinity (SMOS) mission (Kerr et al., 2001). It is recognized that the brightness temperature (TB) received by the microwave radiometers is related to SM, land surface roughness, vegetation parameters and so on. Thus, the strategy of simultaneously estimating several surface variables from passive microwave remote sensing observations is commonly applied. Generally, this strategy is usually based on the inversion of a microwave emission model or a radiative transfer model (RTM). A global optimization algorithm is usually unitized to search the solutions of the inverse problem by constructing a cost function. We call this algorithm the cost function algorithm. The RTMs represent the physical process of interaction between the microwave signal with the land surface parameters, and the optimization algorithm can most probably derive the globally optimal solution by numerous iterative computing. However, this traditional cost function algorithm uses the sole "optimal estimate" to represent the retrieved variable's values, while their confidential intervals and uncertainties cannot be derived from the approach. Considering this problem, the author previously presented a probabilistic inversion algorithm for SM estimation using active microwave remote sensing ( $\mathrm{Ma}$ et al., 2016). The probabilistic inversion (PI) approach is able to derive the posterior probability distribution of SM and to quantify the uncertainty in SM inversion. Thus, one of the main purposes of the present research is to verify the feasibility of the PI on the use of passive microwave through its proper improvement.

Besides, most of the presently released SM products based on passive microwave remote sensing are derived from the space-borne sensors. These products possess a coarse spatial resolution which limits the application of the products in watershed or oasis scaled regions. The airborne microwave radiometers can overcome this limitation, providing moderate or high spatial resolution soil moisture estimates. In many large-scale SM calibration/validation experiments, the airborne radiometers are widely used to provide SM estimates. For instance, Polarimetric Scanning Radiometer (PSR) (Jackson et al., 2002), Electronically Steered Thinned Aperture Radiometet (ESTAR) (Jackson et al., 1999) were used in South Great Plains (SGP) experiments (Jackson and Hsu, 2001; Famiglietti et 
Hydrol. Earth Syst. Sci. Discuss., doi:10.5194/hess-2017-34, 2017

Manuscript under review for journal Hydrol. Earth Syst. Sci.

Discussion started: 13 February 2017

(c) Author(s) 2017. CC-BY 3.0 License.

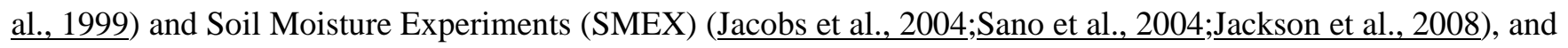
Polarimtric L-band Multi-beam Radiometer (PLMR) was used in National Airborne Field Experiment (NAFE) (Panciera et al., 2008; Merlin et al., 2008) and Soil Moisture Active and Passive Experiments (SMAPEx) (Panciera et al., 2014). PSR provide C-and X-band radiometer observations which are sensitive to SM but also to vegetation. The PLMR can provide L-band TB which is less influenced by the vegetation (Escorihuela et al., 2010; $\underline{\text { Schwank }}$ et al., 2005). As well as, the PLMR sensor operates at dual-polarized and multi-angular configuration, enhancing the observation ability. During the Heihe Watershed Allied Telemetry Experiment Research (HiWATER) (Li et al., 2013), PLRM was applied in SM observation and several datasets were obtained. Besides, a large amount of ground observations were simultaneously obtained (Wang et al., 2013), which provided rich dataset for the validation of remote sensing algorithm and products.

Furthermore, it is commonly recognized that the estimation of surface roughness is the most crucial issue in SM estimation based on microwave remote sensing (Martens et al., 2015; Saleh et al., 2009) because of its high sensitivity to the microwave observations ( $\mathrm{Li}$ et al., 2015; Wang et al., 2016; Ma et al., 2017; Neelam and Mohanty, 2015). Generally, the roughness can be classified into two categories, the physically based roughness and effective roughness. Measuring the roughness costs huge work and time, and it usually cannot be directly used in surface emission modeling and soil parameter inversion. Thus, the effective roughness ( $\mathrm{Hr}$ ) is widely applied. The $\mathrm{Hr}$ cannot be measured directly, and several study parameterized it as the function of measured roughness at L-band (Tsan and Schmugge, 1987; Wigneron et al., 2001), but these parameterizations needs to the measured roughness.

Thus, we usually estimate it prior or simultaneously to the estimation of SM. Several researchers (Saleh et al., 2007; Panciera et al., 2009; Richard et al., 2009) found that the Hr can be estimated via the linear relations between it and SM. However, the SM is usually the retrieval objective which is unknown. Martens et al (Martens et al., $\underline{2015}$ ) proposed two approaches to estimate Hr. The first approach utilized the TB to estimate effective roughness and the second approach utilized TB and leaf area index (LAI) to estimate the effective roughness.

The present paper intends to utilize two estimation strategies to retrieval SM. The first is the simultaneous estimation of SM, Hr and vegetation water content (VWC). The second utilizes Martens (Martens et al., 2015) approaches to estimated $\mathrm{Hr}$ and then simultaneously estimates SM and VWC. The purpose of this doing is to test whether the prior estimating $\mathrm{Hr}$ can reduce the uncertainty in the inversion and improve the SM estimates under the Bayesian PI framework.

The overall objective of this paper is to comprehensively evaluate the feasibility of Bayesian PI based on the multi-channel PLMR observations over heterogeneous cropland and to provide an estimates of the uncertainty in the inversion. The specific objectives include 1) to quantify the uncertainty in SM inversion and to improve the inversion accuracy via PI, 2) to evaluate of the impacts of different retrieval strategies on inversion uncertainty and accuracy, and 3) to examine the feasibility of Hr estimation approach in two aspects, the reduction of uncertainty and the improvement of the inversion accuracy.

The remainder of the paper is organized as follows. The data used are described in detail in Section 2. The 
Hydrol. Earth Syst. Sci. Discuss., doi:10.5194/hess-2017-34, 2017

Manuscript under review for journal Hydrol. Earth Syst. Sci.

Discussion started: 13 February 2017

(c) Author(s) 2017. CC-BY 3.0 License.

methodology is briefly introduced in Section 3. The results are presented in Section 4. A deep discussion is provided in Section 5, and a summary of the main conclusions is presented in Section 6.

\section{Data and processing}

The study area used in this paper is located in the mid-stream of Heihe River Basin (N 37.5-43, E 97-102), which is the second largest inland river basin of China. The land surface is mainly covered by man-made oasis and Gobi desert. The HiWATER ( $\mathrm{Li}$ et al., 2013) was conducted in 2012. This paper selects a small area (Fig. 1) of the experiment filed which located in the desert-oasis transition zone for SM inversion and validation. The data used in this study includes airborne PLMR data and ground in situ data. The former is used to conduct PI for SM estimation and the latter is used to validate the results.

Fig. 1. The locations of study area and SM in situ campaign.

\subsection{PLMR data and processing}

PLMR is an L-band (frequency $=1.41 \mathrm{GHz}$ ) radiometer, operating at multi-angles $\left( \pm 7^{\circ}, \pm 21.5^{\circ}, \pm 38.5^{\circ}\right)$ and dual polarizations ( $\mathrm{v} \& \mathrm{~h}$ ). Thus it can provide 6-channel observations. During HiWATER, PLMR is conducted in 9 flights to measure the TBs in the middle and upper HRB. Due to differences in flight region and height, the spatial resolutions ranged from 300-750 m. The details of the data can be referred to (Che et al., 2013; Yan et al., 2015).

Due to the effect by radio frequency interference, there exists abnormal point in the collected data. To process this problem, we delete the data that exceed the validity rang ( $>300 \mathrm{~K}$ or $<180 \mathrm{~K}$ ) according to the actual condition of the study area. Then, the point cloud data is converted the raster according its spatial resolution. In this paper the data observed on July 10, 2012 is utilized to conduct SM retrieval experiment because it is found that the data collected in the day possesses the highest quality. The spatial resolution of the selected PLMR data is around 750 $\mathrm{m}$.

\subsection{In situ data}

To provide the validation data for the inversion results, we simultaneously conducted ground in situ campaign concurrent with the airborne experiment. In-situ measurements of SM was collected. Samples of volumetric SM representative of the first $5 \mathrm{~cm}$ of the soil was taken using 6 Stevens Water Hydra Probe (Walker, 2010). These in situ SM measurements were collected along 11 transects of 21 samples (160-m row spacing and 80-m spacing between each sample), with 2 replicates for each sample to capture the short range SM variability, within a 1.6 $\mathrm{km} * 1.6 \mathrm{~km}$ square across Gobi desert-woodland-agricultural fields. All these data can provide validation for approximate 11 PLMR pixels as shown in Fig. 1. Additionally, vegetation (maize) was randomly sampled in the area to obtain VWC. The measured VWC is used to provide the initial value and ranges to model inputs. 
Hydrol. Earth Syst. Sci. Discuss., doi:10.5194/hess-2017-34, 2017

Manuscript under review for journal Hydrol. Earth Syst. Sci.

Discussion started: 13 February 2017

(c) Author(s) 2017. CC-BY 3.0 License.

\section{Methodology}

This paper utilizes a Bayesian PI approach to estimate the SM based on airborne PLMR over vegetated field. The

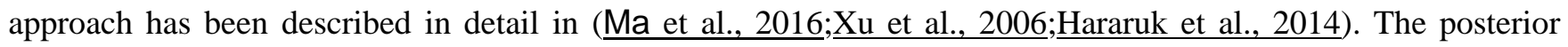
distribution of SM is derived based on Bayesian estimator, and uncertainty in the inversion is represented by several statistics of the posterior distribution of retrieval objectives, including uncertainty (defined as the scale parameter of a general extreme value (GEV) distribution), skewness and kurtosis coefficients; the SM optimal estimates is represented by the maximum likelihood estimation (MLE). The general framework of the Bayesian PI is similar to our previous work in ( $\mathrm{Ma}$ et al., 2016). However, the different aspects of this paper from the previous one can be summarized into 1) different forward models, 2) different data and, 3) different inversion strategies and, 4) comprehensive results evaluation metrics. This paper uses 6-channel PLMR observations and the data has been introduced in Section 2. Here, the forward model, retrieval strategies and results evaluation metrics are briefly described.

\subsection{The L-MEB model}

The L-band Microwave Emission from the Biosphere (L-MEB) model (Wigneron et al., 2007) is applied in this paper to model the microwave emission from the land surface. It is a semi-empirical microwave emission model based on a simplified solution of the zero-order radiative transfer equation, which can be regarded as the simplification of $\tau-\omega$ model (Mo et al., 1982) at L-band. The detailed description of the model can be referred to (Wigneron et al., 2007). This paper only introduces the inputs and outputs of model because it is important for the surface parameters inversion. The model inputs include soil-related, vegetation-related, roughness-related and sensor configuration-related parameters. Table 1 lists all the inputs and their meaning. The outputs of the L-MEB contain v- and h-polarized TBs. The researches of parameter sensitivity analysis ( $\mathrm{Li}$ et al., 2015; Wang et al., 2016; Ma et al., 2017; Neelam and Mohanty, 2015) demonstrates that SM, Hr and VWC and effective soil temperature $\left(\mathrm{T}_{\text {eff }}\right)$ are the most sensitive parameter for TB. Indeed, the $\mathrm{T}_{\text {eff }}$ is function of SM and soil temperature and it can be estimated via parameterization scheme proposed by (Wigneron et al., 2007). The sensitivity of Teff is associated to the SM and soil temperature (Ma et al., 2017).Thus, this paper focuses on the estimation of SM, Hr and VWC.

\section{Table 1. The list of inputs of L-MEB.}

\subsection{Retrieval of SM, Hr and VWC (3P)}

The complete Bayesian PI process contains several key steps, to determine prior information of retrieval objectives (to determine the ranges and initial values of the retrieval objectives), to construct likelihood function, to derive posterior distribution and quantify uncertainty, to get optimal estimates from the posterior distribution.

The ranges and initial values of $\mathrm{SM}\left(\mathrm{SM}_{0}\left(\mathrm{~m}^{3} / \mathrm{m}^{3}\right)\right)$ and $\mathrm{VWC}\left(\mathrm{VWC}_{0}\left(\mathrm{~kg} / \mathrm{m}^{2}\right)\right)$ are set according to 
Hydrol. Earth Syst. Sci. Discuss., doi:10.5194/hess-2017-34, 2017

Manuscript under review for journal Hydrol. Earth Syst. Sci.

Discussion started: 13 February 2017

(c) Author(s) 2017. CC-BY 3.0 License.

investigation during HiWATER and those of roughness parameter $\left(\mathrm{Hr}(-), \mathrm{Hr}_{0}\right)$ are given according to the investigation in ( $\mathrm{Li}$ et al., 2015). The simultaneous estimation of 3 parameters is called the 3P estimation strategy. All these retrieval objectives are assumed to uniformly distribute. The parameter ranges and initial values are listed as following.

$$
\begin{array}{lr}
0.05 \leq \mathrm{SM} \leq 0.50 & \mathrm{SM}_{0}=0.24 \\
0.1 \leq \mathrm{Hr} \leq 1.50 & \mathrm{Hr}_{0}=0.6 \\
0.02 \leq \mathrm{VWC} \leq 6.00 & \mathrm{VWC}_{0}=1.2
\end{array}
$$

The other insensitive parameters for L-MEB model are set to constants according to our experiment investigation as shown in Table 1.

The construction of likelihood function is based a cost function which is minimizing the differences between the 6- channels PLMR observed TBs and corresponding TBs simulated by L-MEB. The uncertainty quantification and MLE is very similar to the doing in (Ma et al., 2016). Thus, the details of constructing cost function, iteration process and MLE can be referred to (Ma et al., 2016).

\subsection{Retrieval of SM and VWC (2P)}

This retrieval strategy firstly estimates Hr using Martens (Martens et al., 2015) proposed approaches as shown in 185 Eqs. (2) \& (3):

$$
\begin{aligned}
& H_{r p}\left(T_{p}\right)=\left(a_{1 p}+a_{2 p} T_{p}\right)^{a_{3 p}} \\
& H_{r p e}\left(T_{p}\right)=\left(a_{1 p}+a_{2 p} T_{p}+a_{4 p} L A I\right)^{a_{3 p}}
\end{aligned}
$$

where $\mathrm{H}_{\mathrm{rp}}$ and $\mathrm{H}_{\mathrm{rpe}}$ are $\mathrm{Hr}$ estimated using different methods; $a_{1 \mathrm{p}}, a_{2 \mathrm{p}}, a_{3 \mathrm{p}}, a_{4 \mathrm{p}}$ (p represents polarization, $\mathrm{h}, \mathrm{v}$, ) are empirical coefficients which are polarization-dependent; LAI is leaf area index which related to the VWC. For simplicity, we assume $\mathrm{H}_{\mathrm{rh}}=\mathrm{H}_{\mathrm{rv}}$ and use the values of $a_{1 \mathrm{~h}}, a_{2 \mathrm{~h}}, a_{3 \mathrm{~h}}$ and $a_{4 \mathrm{~h}}$ and average values of three incidence- angular TBs to calculate the Hr. The range of LAI is $3<=\mathrm{LAI}<=4$ at the experimental region, thus Eqs. (2) \& (3) are:

$$
\begin{aligned}
& \mathrm{H}_{\mathrm{rh}}\left(\mathrm{TB}_{\mathrm{h}}\right)=\left(-2.06+\frac{0.0111\left(\mathrm{~TB}_{\mathrm{h} 7}+\mathrm{TB}_{\mathrm{h} 21.5}+\mathrm{TB}_{\mathrm{h} 38.5}\right)}{3}\right)^{2} \\
& \mathrm{H}_{\mathrm{rh}}\left(\mathrm{TBE}_{\mathrm{h}}\right)=\left(-1.58+\frac{0.0117\left(\mathrm{~TB}_{\mathrm{h} 7}+\mathrm{TB}_{\mathrm{h} 21.5}+\mathrm{TB}_{\mathrm{h} 38.5}\right)}{3}-0.18 \mathrm{LAI}\right)^{2}
\end{aligned}
$$

According to the investigation of LAI and VWC of the study area, we get the relation between LAI and VWC as Eq. (4):

$$
\mathrm{LAI}=1.67 \mathrm{VWC}+1.4
$$

Then the estimated $\mathrm{Hr}$ is used as one of inputs of L-MEB to estimate SM and VWC simultaneously. The estimation strategy of SM and VWC utilizing the Eq. (2') calculated Hr is called 2P_TB strategy and that utilizing the Eq. (3') calculated $\mathrm{Hr}$ is called 2P_TBE strategy. 
Hydrol. Earth Syst. Sci. Discuss., doi:10.5194/hess-2017-34, 2017

Manuscript under review for journal Hydrol. Earth Syst. Sci.

Discussion started: 13 February 2017

\subsection{Validation metrics}

Different from the point-pixel comparison validation strategy, all the ground measurements falling into a certain PLMR pixel are averaged to get pixel scale ground reference value. This value is applied to compare with the PI estimated SM. The standard validation indices of SMAP SM products (Entekhabi et al., 2010) and relative error (RE), including RMSE, the mean bias, the unbiased RMSE (ubRMSE), and coefficient of determination $\left(\mathrm{R}^{2}\right)$ are used. The definitions of the validation indices as following:

$$
\begin{aligned}
& R M S E=\sqrt{E\left[\left(\mathrm{SM}_{\text {est }}-\mathrm{SM}_{\text {ref }}\right)^{2}\right]} \\
& \text { Bias }=E\left[\mathrm{SM}_{\text {est }}\right]-E\left[\mathrm{SM}_{r e f}\right] \\
& u b R M S E=\sqrt{E\left[\left(\left(\mathrm{SM}_{e s t}-E\left[\mathrm{SM}_{\text {est }}\right]\right)-\left(\mathrm{SM}_{\text {ref }}-E\left[\mathrm{SM}_{\text {ref }}\right]\right)\right)^{2}\right]} \\
& R=E\left[\left(\mathrm{SM}_{\text {est }}-E\left[\mathrm{SM}_{e s t}\right]\right)\left(\mathrm{SM}_{\text {ref }}-E\left[\mathrm{SM}_{\text {ref }}\right]\right)\right] /\left(\sigma_{\text {est }} \cdot \sigma_{\text {ref }}\right) \\
& R E=E\left[\frac{\text { abs }\left(\mathrm{SM}_{\text {est }}-\mathrm{SM}_{r e f}\right)}{\left.\mathrm{SM}_{\text {ref }}\right)}\right] * 100 \%
\end{aligned}
$$

in above equations: $\mathrm{SM}_{e s t}$ and $\mathrm{SM}_{\text {ref }}$ represent the estimated and ground observed $\mathrm{SM}$ values, respectively; $E[$. ] and $a b s$ are the expectation and absolute value operators, respectively; $\sigma_{e s t}$ and $\sigma_{\text {ref }}$ are the standard deviations of the estimated and ground measured SM, respectively.

\section{Results and validation}

\subsection{Posterior distribution of $\mathrm{SM}$ and uncertainty in the inversion}

Fig. 2 shows the probability distribution of $3 \mathrm{P}$ retrieval objectives. The uncertainty, skewness and kurtosis coefficients of SM posterior distribution are $0.079 \mathrm{~m}^{3} / \mathrm{m}^{3}, 0.715$ and 2.788 , respectively. This uncertainty index describes the dispersion of the SM posterior distribution. It does not represent the error in SM estimates but it may cause the error in SM estimates. The skewness and kurtosis coefficients quantitatively describe the shape of the posterior distribution. The shape of SM posterior distribution and the value of skewness coefficient shown that SM is positively skewed. The kurtosis coefficient is larger than that of uniform distribution but smaller than that of normal distribution. Thus, SM is distributed non-uniformly and non-normally, indicating that SM distribution is well constrained by the PI but the inversion exists uncertainty. The figure also shows that SM observation value and MLE are very closed, which means the MLE may well represent the SM estimates.

Fig. 2 The probability distribution of 3 P retrieval objectives

Figs. $3 \& 4$ show the results of $2 \mathrm{P}$ strategies estimated retrieval objectives. For the comparability, we select the results of the same pixel (pixel 5) as result of 3P. It can be seen that the SM distributions exhibit larger uncertainty index and smaller kurtosis, which means that the SM estimations of 2P strategies exist larger uncertainty 
Hydrol. Earth Syst. Sci. Discuss., doi:10.5194/hess-2017-34, 2017

Manuscript under review for journal Hydrol. Earth Syst. Sci.

Discussion started: 13 February 2017

(c) Author(s) 2017. CC-BY 3.0 License.

than that of 3P estimation. This uncertainty may be caused by the estimation of Hr. However, the VWC distributions of $2 \mathrm{P}$ strategies show smaller uncertainty and larger kurtosis. This is because the Hr estimations in $2 \mathrm{P}$ strategies are related to VWC, which may enhances the sensitivity of VWC on TB.

Fig. 3 The probability distribution of 2P_TB retrieval objectives

Fig. 4 The probability distribution of 2P_TBE retrieval objectives

\subsection{Optimal estimation and validation of $S M$}

Based on the posterior distribution of SM, the MLE of GEV is applied to represent the optimal estimates of SM. Figs. 5-7 show the comparison of retrieved and ground measured SM. The error metrics are also shown in the figures. It can be observed that all the retrieval strategies get satisfactory performances with very small RE, RMSE and ubRMSE and relative large $\mathrm{R}^{2}$ values. These retrievals have exceeded the expected accuracies of $0.04 \mathrm{~m}^{3} / \mathrm{m}^{3}$ of SMAP and SMOS missions. Comparatively, the $2 \mathrm{P}$ retrieval strategies result in more excellent results than that results from 3P strategy. The 2P strategies slightly overestimate the SM with positive bias but the 3P strategy leads to a slightly underestimation of SM.

Fig. 5 The comparison of 3P strategy estimated and ground measured SM.

Fig. 6 The comparison of 2P_TB strategy estimated and ground measured SM.

Fig. 7 The comparison of 2P_TBE strategy estimated and ground measured SM.

\subsection{Evaluation and improvements of Simulated TB}

The optimized soil and vegetation variables obtained via MLE are used to model the TB with L-MEB model, and then the simulated TBs are compared against those observed by PLMR (Figs. 8 -10), Small RMSE and large $\mathrm{R}^{2}$ are observed, indicating that the simulated TBs are improved by this Bayesian PI. Due to the lack of available $\mathrm{Hr}$ and sufficient VWC measurements, we cannot directly compare these results with those modeled from the originally observed surface variables. However, Yan (Yan et al., 2015) conducted parameter calibration for L-MEB model utilizing the same dataset, the findings of which can provide reference for our work. By comprising, we can find that our results are similar even better than those obtained by Yan (Yan et al., 2015). Thus, the Bayesian PI presented in this paper has ability of improving the performance of L-MEB.

Fig.8. The comparison of PLMR observed TB with those simulated by MLE variables under 3P strategy. Fig.9. The comparison of PLMR observed TB with those simulated by MLE variables under 2P_TB strategy. 
Hydrol. Earth Syst. Sci. Discuss., doi:10.5194/hess-2017-34, 2017

Manuscript under review for journal Hydrol. Earth Syst. Sci.

Discussion started: 13 February 2017

(c) Author(s) 2017. CC-BY 3.0 License.

Fig.10. The comparison of PLMR observed TB with those simulated by MLE variables under 2P_TBE strategy.

\section{Discussion}

The paper performs an experiment on SM estimation based on a Bayesian PI and 6-channel airborne PLMR observations collected during HiWATER. The result is validated by the corresponding ground measurement. The inversion uncertainty is quantified and the inversion accuracy exceeds the expected accuracies of SMAP and SMOS missions. However, several key points in SM estimation based on microwave remote sensing is needed to further discuss and address.

The first import issue is the uncertainty quantification of SM inversion. As described in Section 3, the approach Bayesian PI presented in this paper is similar but not identical to our previous work in (Ma et al., 2016). Thus, new findings are obtained in this work associating the uncertainty quantification. In (Ma et al., 2016), we discussed the quantification of SM inversion based on X-band SAR and concluded that the use of X-band SAR on SM estimation over vegetated soils exhibited relative large uncertainty which was related to the uncertainty in scattering model and inversion algorithm at pixel scale, as well as to the limitation of X-band SAR. The inversion uncertainty of this paper is smaller than that of ( $\mathrm{Ma}$ et al., 2016). This paper utilizes 6-channel observation to better constrain the posterior distribution of SM, making the inversion uncertainty decrease. Besides, the number of unknowns of this inversion is less than that in the previous inversion, especially this inversion utilizes one "effective" roughens parameter instead of two physically based roughness parameters in the previous study. Third, the L-band passive microwave observations are applied in this inversion. On the one hand, the passive microwave observation is more sensitive to $\mathrm{SM}(\underline{\mathrm{Ma} \text { et al., 2017) }}$ while the active microwave observation is more sensitive to roughness (Ma et al., 2015). On the other hand, it is commonly recognized that L-band is more suitable than X-band for SM estimation over vegetated soil (Rosenqvist et al., 2007; Chen et al., 2010; Panciera et al., 2014;Zhao et al., 2015).

Secondly, the issue of surface roughness estimation is one of the most crucial issues in SM estimation based on microwave remote sensing. The roughness parameter $\mathrm{Hr}$ used in L-MEB model is an "effective" parameter which cannot be measured directly. This paper utilizes two strategies (3P \&2P) to estimate it. We have seen from the results that the 2P strategies result in an increasing uncertainty in SM inversion, but a higher accuracy in SM optimal estimation. These observations are not contradictory because we have stated that the uncertainty in SM inversion is not the error of the SM estimates. The uncertainty originates from the retrieval algorithm and data source (Ma et al., 2016). It represents constraining ability of algorithm and data to the posterior estimates of the retrieval objectives. In the $2 \mathrm{P}$ retrieval strategies, a variable with uncertainty, $\mathrm{Hr}$, is estimated by $\mathrm{TB}$ or TB and LAI, and it gets a determined value. Thus, the uncertainty in $\mathrm{Hr}$ estimation is transformed to and re-assigned by the two other variables, SM and VWC. The error of the optimal estimates of SM in this paper is described by several error metrics. In addition to relating to the uncertainty of the inversion algorithm and data source, the estimation error is related to retrieval and validation strategies, validation dataset and number of the unknowns. In this paper, the sole 
Hydrol. Earth Syst. Sci. Discuss., doi:10.5194/hess-2017-34, 2017

Manuscript under review for journal Hydrol. Earth Syst. Sci.

Discussion started: 13 February 2017

(c) Author(s) 2017. CC-BY 3.0 License.

difference in $3 \mathrm{P}$ and $2 \mathrm{P}$ strategies is the difference of the number of the unknowns and retrieval strategy. The $2 \mathrm{P}$ retrieval strategies result in a more desirable SM estimation accuracy, indicating that 1) the Hr estimation approaches proposed by Martens (Martens et al., 2015) is feasible to SM estimation, and 2) the reducing of unknowns can enhance the estimation accuracy of SM. Overall, we can conclude that both the two strategies utilized in this paper result in desirable SM estimations.

The third issue is how many retrieval objectives should be simultaneously estimated and how many observations should be used. The development of multi-frequency multi-angle and multi-polarized microwave sensors (Oza et al., 2006; Notarnicola and Posa, 2003; Dong et al., 2014), provides very rich data for SM estimation using multi-channels. PLMR provides 6-channel observations to estimate three or two unknowns. Theoretically, three unrelated observations can provide sufficient data for estimating three unknowns. That is, we can simultaneously estimate SM, Hr and VWC using any combination of 3-channel PLMR observations. What we concern is that the differences in uncertainty reduction and accuracy improvement under the use of different observations. In this paper, we don't conducted the related experiments. However, research (Li et al., 2014) showed that the more use of observations, the result was more accurate. We have discussed that the $2 \mathrm{P}$ retrieval strategies result in larger uncertainty in SM inversion but more accurate SM estimates. Besides, researchers utilized spectral index derived from optical remote sensing data, e.g., NDVI, to estimate VWC and then simultaneously estimate $\mathrm{SM}$ and $\mathrm{Hr}$. The premise of these doings is the accurate estimation of $\mathrm{Hr}$ or VWC. And these doing is expected to introduce a larger uncertainty in SM inversion and get a more accurate SM estimates.

Finally, similar research was conducted to estimate SM using the same PLMR data ( $\mathrm{Li}$ et al., 2014). The authors explored three retrieval strategies using 1P, 2P and 3P and demonstrated that the 3P using 6-channel strategy led to the best results of SM estimation. The conclusion is consistent to that we find in this paper. However, several improved points can be observed in the present paper. Firstly, the previous one utilized traditional point-estimation approach which only got the 'optimal' estimates of SM, while the present Bayesian PI results in the posterior distribution of SM and uncertainty estimation of the inversion。 The inversion accuracy is better than that of the previous research. Secondly, the present work utilizes pure PLMR data but the previous study combined PLMR and MODIS data. Third, in 2P strategy the present work estimate $\mathrm{Hr}$ using $\mathrm{TB}$, but the previous work set it as constant, which no doubt led to larger uncertainty. In 3P strategy, the present work determine the variance of the PLMR observation according actual data but the previous work artificially set its value.

\section{Conclusions}

The Bayesian PI has been demonstrated its ability of improving accuracy and quantifying uncertainty in the SM estimation based on active microwave remote sensing. Meanwhile, the L-band radiometry has been witnessed a huge potential in monitoring and estimating soil moisture over vegetated soils. The present paper combines the merit of Bayesian PI with multi-channel airborne PLMR observations to develop highly accurate SM estimates as well as to quantify the uncertainty in SM inversion. Various retrieval strategies and several retrieval experiments 
Hydrol. Earth Syst. Sci. Discuss., doi:10.5194/hess-2017-34, 2017

Manuscript under review for journal Hydrol. Earth Syst. Sci.

Discussion started: 13 February 2017

(c) Author(s) 2017. CC-BY 3.0 License.

are conducted based on PLMR data collected on July 10, 2012 during HiWATER experiments. The uncertainty in SM inversion is estimated and highly accurate SM estimates are obtained through validating by simultaneous ground measurements. The main finding can be summarized as following: (1) The 6-channel L-band passive microwave observations can result in smaller uncertainty in SM inversion and more accurate SM estimates than the X-band SAR observations conducted in previous work. The uncertainties in SM inversion are 0.079, 0.092 and $0.094 \mathrm{~m}^{3} / \mathrm{m}^{3}$ for 3P, 2P_TB and 2P_TBE strategies, respectively. All of the SM estimation accuracies are with the RMSE and ubRMSE less than $0.03 \mathrm{~m}^{3} / \mathrm{m}^{3}$, which have exceeded the $0.04 \mathrm{~m}^{3} / \mathrm{m}^{3}$ of SMAP and SMOS missions target accuracies. (2) In addition to quantify uncertainty in SM inversion and improve SM estimation accuracy, the Bayesian PI can improve the simulation performance of L-MEB model via MLE, hence decreasing the differences between L-MEB simulation and PLMR observation. This function is similar to the calibration of model parameter. (3) Both the 3P and 2P strategies derive satisfactory SM estimates as long as they obtain an accurate roughness estimation. But different retrieval strategies may result in difference in SM inversion uncertainties. (4) The Martens (Martens et al., 2015) proposed approach can be used to estimate roughness from TB directly. And the estimated roughness can assist to improve the SM estimation. Overall, the present Bayesian PI combining multi-channel PLMR observations has obtained a desirable SM estimation and uncertainty quantification, which may offer an insight into the future SM inversion based on passive microwave remote sensing.

\section{Acknowledgement}

This study is jointly supported by the National Natural Science Foundation of China under Grant 91425303 and Key Research Program of Frontier Sciences, Chinese Academy of Sciences, under Grant QYZDY-SSWDQC011.

\section{References}

Calvet, J. C., Wigneron, J. P., Walker, J., Karbou, F., Chanzy, A., and Albergel, C.: Sensitivity of Passive Microwave Observations to Soil Moisture and Vegetation Water Content: L-Band to W-Band, IEEE Transactions on Geoscience and Remote Sensing, 49, 1190-1199, Doi 10.1109/Tgrs.2010.2050488, 2011.

Chaouch, N., Leconte, R., Magagi, R., Temimi, M., and Khanbilvardi, R.: Multi-Stage Inversion Method to Retrieve Soil Moisture from Passive Microwave Measurements over the Mackenzie River Basin, Vadose Zone Journal, 12, Doi 10.2136/Vzj2012.0134, 2013.

Che, T., Li, X., Gao, Y., and Jeff, W.: HiWATER: Dataset of airborne microwave radiometers (L bands) mission in the middle reaches of the Heihe River Basin on Jun. 30, 2012, Heihe Plan Science Data Center, 10.3972/hiwater.013.2013.db doi:10.3972/hiwater.013.2013.db, 2013.

Chen, L., Shi, J. C., Wigneron, J. P., and Chen, K. S.: A Parameterized Surface Emission Model at L-Band for Soil Moisture Retrieval, Ieee Geoscience and Remote Sensing Letters, 7, 127-130, Doi 10.1109/Lgrs.2009.2028443, 2010.

Dong, X., Liu, H., Wang, Z., Shi, J., and Zhao, T.: WCOM: The mission concept and payloads of a global water cycle observation mission, 2014 IEEE Geoscience and Remote Sensing Symposium, 2014, 3338-3341,

Entekhabi, D., Reichle, R. H., Koster, R. D., and Crow, W. T.: Performance Metrics for Soil Moisture Retrievals and Application 
Hydrol. Earth Syst. Sci. Discuss., doi:10.5194/hess-2017-34, 2017

Hydrology and

Manuscript under review for journal Hydrol. Earth Syst. Sci.

Discussion started: 13 February 2017

Requirements, Journal of Hydrometeorology, 11, 832-840, 10.1175/2010JHM1223.1, 2010.

Escorihuela, M. J., Chanzy, A., Wigneron, J. P., and Kerr, Y. H.: Effective soil moisture sampling depth of L-band radiometry: A case study, Remote Sensing of Environment, 114, 995-1001, DOI 10.1016/j.rse.2009.12.011, 2010.

Famiglietti, J. S., Devereaux, J. A., Laymon, C. A., Tsegaye, T., Houser, P. R., Jackson, T. J., Graham, S. T., Rodell, M., and van Oevelen, P. J.: Ground-based investigation of soil moisture variability within remote sensing footprints during the Southern Great Plains 1997 (SGP97) Hydrology Experiment, Water Resources Research, 35, 1839-1851, Doi 10.1029/1999wr900047, 1999.

Hararuk, O., Xia, J. Y., and Luo, Y. Q.: Evaluation and improvement of a global land model against soil carbon data using a Bayesian Markov chain Monte Carlo method, Journal of Geophysical Research-Biogeosciences, 119, 403-417, 10.1002/2013JG002535, 2014.

Jackson, T. J., Le Vine, D. M., Hsu, A. Y., Oldak, A., Starks, P. J., Swift, C. T., Isham, J. D., and Haken, M.: Soil moisture mapping at regional scales using microwave radiometry: The Southern Great Plains Hydrology Experiment, IEEE Transactions on Geoscience and Remote Sensing, 37, 2136-2151, 1999.

Jackson, T. J., and Hsu, A. Y.: Soil moisture and TRMM microwave imager relationships in the Southern Great Plains 1999 (SGP99) Experiment, IEEE Transactions on Geoscience and Remote Sensing, 39, 1632-1642, Doi 10.1109/36.942541, 2001.

Jackson, T. J., Gasiewski, A. J., Oldak, A., Klein, M., Njoku, E. G., Yevgrafov, A., Christiani, S., and Bindlish, R.: Soil moisture retrieval using the C-band polarimetric scanning radiometer during the Southern Great Plains 1999 Experiment, IEEE Transactions on Geoscience and Remote Sensing, 40, 2151-2161, 2002.

Jackson, T. J., Moran, M. S., and O'Neill, P. E.: Introduction to Soil Moisture Experiments 2004 (SMEX04) Special Issue, Remote Sensing of Environment, 112, 301-303, DOI 10.1016/j.rse.2007.01.021, 2008.

Jacobs, J. M., Mohanty, B. P., Hsu, E. C., and Miller, D.: SMEX02: Field scale variability, time stability and similarity of soil moisture, Remote Sensing of Environment, 92, 436-446, DOI 10.1016/j.rse.2004.02.017, 2004.

Kerr, Y. H., Waldteufel, P., Wigneron, J. P., Martinuzzi, J., Font, J., and Berger, M.: Soil moisture retrieval from space: the Soil Moisture and Ocean Salinity (SMOS) mission, IEEE Transactions on Geoscience and Remote Sensing, 39, 1729-1735, 10.1109/36.942551, 2001.

395 Kim, J., Mohanty, B. P., and Shin, Y.: Effective soil moisture estimate and its uncertainty using multimodel simulation based on Bayesian Model Averaging, Journal of Geophysical Research-Atmospheres, 120, 8023-8042, 10.1002/2014JD022905, 2015.

Koike, T., Nakamura, Y., Kaihotsu, I., Davaa, G., Matsuura, N., Tamagawa, K., and Fujii, H.: DEVELOPMENT OF AN ADVANCED MICROWAVE SCANNING RADIOMETER (AMSR-E) ALGORITHM FOR SOIL MOISTURE AND VEGETATION WATER CONTENT, Doboku Gakkai Ronbunshuu B, 48, 217-222, 2004.

Li, D., Jin, R., Che, T., Walker, J. P., Gao, Y., Ye, N., and Wang, S.: Soil Moisture Retrieval from Airborne PLMR and MODIS Productsinthe ZhangyeOasisof MiddleStream ofHeihe River Basin, China, Advances in Earth Science (In Chinese), 29, 295-305, 2014.

Li, D., Jin, R., Zhou, J., and Kang, J.: Analysis and Reduction of the Uncertainties in Soil Moisture Estimation With the L-MEB Model Using EFAST and Ensemble Retrieval, IEEE Geoscience and Remote Sensing Letters, 12, 1337-1341, 10.1109/LGRS.2015.2399776, 2015. Li, X., Cheng, G., Liu, S., Xiao, Q., Ma, M., Jin, R., Che, T., Liu, Q., Wang, W., Qi, Y., Wen, J., Li, H., Zhu, G., Guo, J., Ran, Y., Wang, S.,

Zhu, Z., Zhou, J., Hu, X., and Xu, Z.: Heihe Watershed Allied Telemetry Experimental Research (HiWATER): Scientific Objectives and Experimental Design, Bulletin of the American Meteorological Society, 9, 1145-1160, 10.1175/bams-d-12-00154, 2013.

Ma, C., Li, X., and Wang, S.: A Global Sensitivity Analysis of Soil Parameters Associated With Backscattering Using the Advanced Integral 
Hydrol. Earth Syst. Sci. Discuss., doi:10.5194/hess-2017-34, 2017

Hydrology and

Manuscript under review for journal Hydrol. Earth Syst. Sci.

Discussion started: 13 February 2017

Equation Model, IEEE Transactions on Geoscience and Remote Sensing, 53, 5613-5623, 10.1109/TGRS.2015.2426194, 2015.

Ma, C., Li, X., Notarnicola, C., Wang, S., and Wang, W.: Uncertainty Quantification of Soil Moisture Estimations Based on a Bayesian Probabilistic Inversion, IEEE Transactions on Geoscience and Remote Sensing, Minor revision, 2016.

Ma, C., Li, X., Wang, J., Wang, C., Duan, Q., and Wang, W.: A Comprehensive Evaluation of Microwave Emissivity and Brightness Temperature Sensitivities to Soil Parameters Using Qualitative and Quantitative Sensitivity Analyses, IEEE Transactions on Geoscience and Remote Sensing, 55, 1025-1038, 10.1109/TGRS.2016.2618903, 2017.

Martens, B., Lievens, H., Colliander, A., Jackson, T. J., and Verhoest, N. E. C.: Estimating Effective Roughness Parameters of the L-MEB Model for Soil Moisture Retrieval Using Passive Microwave Observations From SMAPVEX12, IEEE Transactions on Geoscience and Remote Sensing, 53, 4091-4103, 10.1109/Tgrs.2015.2390259, 2015.

Merlin, O., Walker, J. P., Kalma, J. D., Kim, E. J., Hacker, J., Panciera, R., Young, R., Summerell, G., Hornbuckle, J., and Hafeez, M.: The NAFE'06 data set: Towards soil moisture retrieval at intermediate resolution, Advances in Water Resources, 31, 1444-1455, 2008.

Mo, T., Choudhury, B. J., Schmugge, T. J., Wang, J. R., and Jackson, T. J.: A model for microwave emission from vegetation-covered fields, Journal of Geophysical Research, 87, 11229, 10.1029/JC087iC13p11229, 1982.

Neelam, M., and Mohanty, B. P.: Global sensitivity analysis of the radiative transfer model, Water Resources Research, 51, 2428-2443, 10.1002/2014WR016534, 2015.

Njoku, E. G., Jackson, T. J., Lakshmi, V., Chan, T. K., and Nghiem, S. V.: Soil moisture retrieval from AMSR-E, IEEE Transactions on Geoscience and Remote Sensing, 41, 215-229, 10.1109/TGRS.2002.808243, 2003.

Notarnicola, C., and Posa, F.: Development of an algorithm for the Bayesian fusion of multi-angle, multi-polarisation and multi-frequency remotely sensed data, Geoinformation for European-Wide Integration, 279-286, 2003.

Oza, S. R., Singh, R. P., Dadhwal, V. K., and Desai, P. S.: Large area soil moisture estimation and mapping using space-borne multi-frequency passive microwave data, Photonirvachak-Journal of the Indian Society of Remote Sensing, 34, 343-350, 2006.

Panciera, R., Walker, J. P., Kalma, J. D., Kim, E. J., Hacker, J. M., Merlin, O., Berger, M., and Skou, N.: The NAFE'05/CoSMOS data set: Toward SMOS soil moisture retrieval, downscaling, and assimilation, IEEE Transactions on Geoscience and Remote Sensing, 46, 736-745, 2008.

Panciera, R., Walker, J. P., Kalma, J. D., Kim, E. J., Saleh, K., and Wigneron, J. P.: Evaluation of the SMOS L-MEB passive microwave soil moisture retrieval algorithm, Remote Sensing of Environment, 113, 435-444, DOI 10.1016/j.rse.2008.10.010, 2009.

Panciera, R., Walker, J. P., Jackson, T. J., Gray, D. A., Tanase, M. A., Ryu, D., Monerris, A., Yardley, H., Rudiger, C., Wu, X. L., Gao, Y., and Hacker, J. M.: The Soil Moisture Active Passive Experiments (SMAPEx): Toward Soil Moisture Retrieval From the SMAP Mission, IEEE Transactions on Geoscience and Remote Sensing, 52, 490-507, Doi 10.1109/Tgrs.2013.2241774, 2014.

Richard, d., Jeu, Holmes, R. H., Thomas, Panciera, R., and Walker, J. P.: Parameterization of the Land Parameter Retrieval Model for LBand Observations Using the NAFE'05 Data Set, IEEE Geoscience and Remote Sensing Letters, 6, 630-634, Doi 10.1109/Lgrs.2009.2019607, 2009.

Rosenqvist, A., Shimada, M., Ito, N., and Watanabe, M.: ALOS PALSAR: A Pathfinder Mission for Global-Scale Monitoring of the Environment, IEEE Transactions on Geoscience and Remote Sensing, 45, 3307-3316, 10.1109/TGRS.2007.901027, 2007.

Saleh, K., Wigneron, J. P., Waldteufel, P., de Rosnay, P., Schwank, M., Calvet, J. C., and Kerr, Y. H.: Estimates of surface soil moisture under 
Hydrol. Earth Syst. Sci. Discuss., doi:10.5194/hess-2017-34, 2017

Manuscript under review for journal Hydrol. Earth Syst. Sci.

grass covers using L-band radiometry, Remote Sensing of Environment, 109, 42-53, 2007.

Saleh, K., Kerr, Y. H., Richaume, P., Escorihuela, M. J., Panciera, R., Delwart, S., Boulet, G., Maisongrande, P., Walker, J. P., and Wursteisen, P.: Soil moisture retrievals at L-band using a two-step inversion approach (COSMOS/NAFE'05 Experiment), Remote Sensing of Environment, 113, 1304-1312, 10.1016/j.rse.2009.02.013, 2009.

Sano, E. E., Assad, E. D., Jackson, T. J., Crow, W., and Hsu, A.: Overview of the Aqua/AMSR-E 2003 soil moisture experiment in Brazil (SMEX03 Brazil), 2004 IEEE International Geoscience and Remote Sensing Symposium, 329-331, 2004.

Schwank, M., Mätzler, C., Guglielmetti, M., and Flühler, H.: L-Band Radiometer Measurements of Soil Water Under Growing Clover Grass,

IEEE Trans. Geosci. Remote Sensing, 43, 2225-2237, 2005.

Shi, J. C., Li, Q., Chen, K. S., Jackson, T., Njoku, E. G., and O'Neills, P.: A numerical simulation of estimating soil moisture with L-band radiometer, Igarss 2001: Scanning the Present and Resolving the Future, Vols 1-7, Proceedings, 25-27, 2001.

Tsan, M., and Schmugge, T. J.: A Parameterization of the Effect of Surface Roughness on Microwave Emission, Geoscience and Remote Sensing, IEEE Transactions on, GE-25, 481-486, 10.1109/TGRS.1987.289860, 1987.

Walker, J. P., Rüdiger, C., Peischl, S., Nan, Y., Bandara, R., Allahmoradi, M., Kerr, Y., Kim, E., Gurney, R., Barrett, D. and Le Marshall, J.: Australian Airborne Cal/val Experiments for SMOS (AACES) - Winter Campaign: Experiment Plan, in, Department of Civil Engineering, Monash University, 171, 2010.

Wang, S., Ma, C., Dong, C., and Zhou, F.: HiWATER: Dataset of ground truth measurements synchronizing with airborne PLMR mission in the Yingke oasis and Huazhaizi desert steppe on July 10, 2012, Heihe Plan Science Data Center, 10.3972/hiwater.054.2013.db doi:10.3972/hiwater.054.2013.db, 2013.

Wang, Z., Che, T., and Liou, Y.-A.: Global Sensitivity Analysis of the L-MEB Model for Retrieving Soil Moisture, IEEE Transactions on Geoscience and Remote Sensing, 54, 2949-2962, 2016.

Wigneron, J. P., Laguerre, L., and Kerr, Y. H.: A simple parameterization of the L-band microwave emission from rough agricultural soils, IEEE Transactions on Geoscience and Remote Sensing, 39, 1697-1707, Doi 10.1109/36.942548, 2001.

465 Wigneron, J. P., Kerr, Y., Waldteufel, P., Saleh, K., Escorihuela, M. J., Richaume, P., Ferrazzoli, P., de Rosnay, P., Gurney, R., Calvet, J. C., Grant, J. P., Guglielmetti, M., Hornbuckle, B., Matzler, C., Pellarin, T., and Schwank, M.: L-band Microwave Emission of the Biosphere (LMEB) Model: Description and calibration against experimental data sets over crop fields, Remote Sensing of Environment, 107, 639-655, DOI 10.1016/j.rse.2006.10.014, 2007.

Xu, T., White, L., Hui, D. F., and Luo, Y. Q.: Probabilistic inversion of a terrestrial ecosystem model: Analysis of uncertainty in parameter estimation and model prediction, Global Biogeochemical Cycles, 20, Artn Gb2007

Doi 10.1029/2005gb002468, 2006.

Yan, S., Jiang, L. M., Chai, L. N., Yang, J. T., and Kou, X. K.: Calibration of the L-MEB Model for Croplands in HiWATER Using PLMR Observation(dagger), Remote Sensing, 7, 10878-10897, 10.3390/rs70810878, 2015.

Zhao, T. J., Shi, J. C., Rajat, B., Thomas, J., Michael, C., Jiang, L. M., Zhang, Z. J., and Lan, H. M.: Parametric exponentially correlated surface emission model for L-band passive microwave soil moisture retrieval, Physics and Chemistry of the Earth, 83-84, 65-74, 10.1016/j.pce.2015.04.001, 2015. 
Hydrol. Earth Syst. Sci. Discuss., doi:10.5194/hess-2017-34, 2017

Manuscript under review for journal Hydrol. Earth Syst. Sci.

Discussion started: 13 February 2017

(c) Author(s) 2017. CC-BY 3.0 License.

Table 1. The list of inputs of L-MEB.

\begin{tabular}{lll}
\hline Parameter & Value & Meaning \\
\hline Freq & 1.41 & Frequency of radiometer $(\mathrm{GHz})$ \\
Theta & $7,21.5,38.5$ & Incidence angle $($ degrees $)$ \\
$\mathrm{SM}$ & Variable & Soil moisture $\left(\mathrm{m}^{3} / \mathrm{m}^{3}\right)$ \\
$\mathrm{T}_{\text {surf }}$ & 300 & Surface soil temperature $(\mathrm{K})$ \\
$\mathrm{T}_{\text {deep }}$ & 285 & Deep soil temperature $(\mathrm{K})$ \\
rob & 1.33 & Soil bulk density $(\mathrm{g} / \mathrm{cm} 3)$ \\
clay & 0.32 & clay content $(0-1)$ \\
sand & 0.495 & sand content $(0-1)$ \\
$* t t_{\mathrm{p}}$ & 1 & Vegetation structure parameter $(-)$ \\
$* \omega_{\mathrm{p}}$ & 0 & Vegetation scattering albedo $(-)$ \\
$\mathrm{vwc}$ & Variable & Vegetation water content $\left(\mathrm{kg} / \mathrm{m}^{2}\right)$ \\
$\mathrm{Tc}$ & 300 & Vegetation temperature $(\mathrm{K})$ \\
$\mathrm{Hr}$ & Variable & Roughness parameter $(-)$ \\
$* \mathrm{Q}_{\mathrm{p}}$ & 0 & Polarization mixing parameter $(-)$ \\
$* \mathrm{~N}_{\mathrm{p}}$ & 0 & Roughness exponent $(-)$ \\
\hline
\end{tabular}

* Subscript $\mathrm{p}(=\mathrm{h}, \mathrm{v})$ represents the polarizations. 
Hydrol. Earth Syst. Sci. Discuss., doi:10.5194/hess-2017-34, 2017

Manuscript under review for journal Hydrol. Earth Syst. Sci.

Discussion started: 13 February 2017

(c) Author(s) 2017. CC-BY 3.0 License.
Hydrology and

Earth System

Sciences

Discussions

(c) (1)

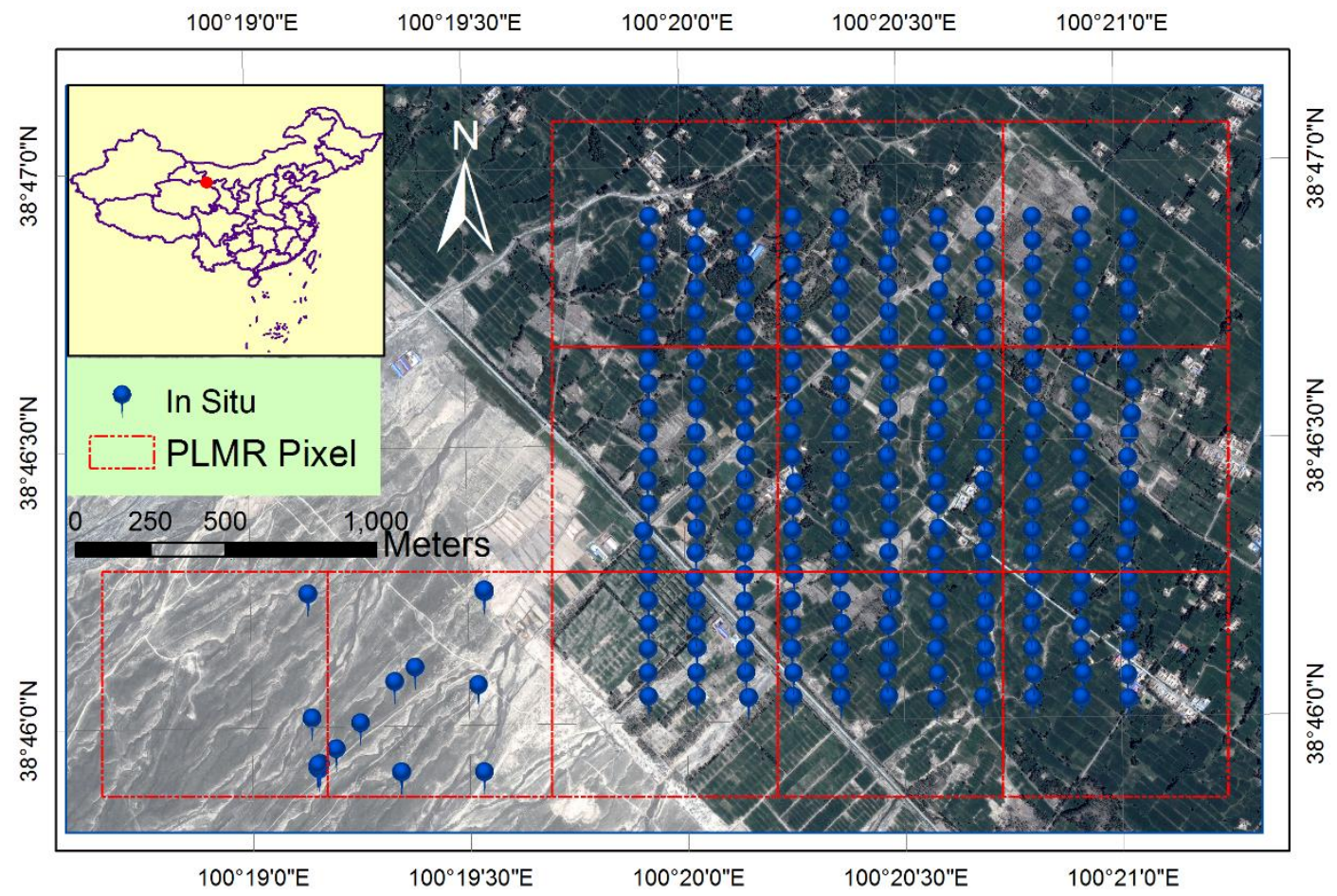

Fig. 1. The locations of study area and SM in situ campaign. 
Hydrol. Earth Syst. Sci. Discuss., doi:10.5194/hess-2017-34, 2017

Manuscript under review for journal Hydrol. Earth Syst. Sci.

Discussion started: 13 February 2017

(c) Author(s) 2017. CC-BY 3.0 License.
Hydrology and

Discussions

(c) (i)
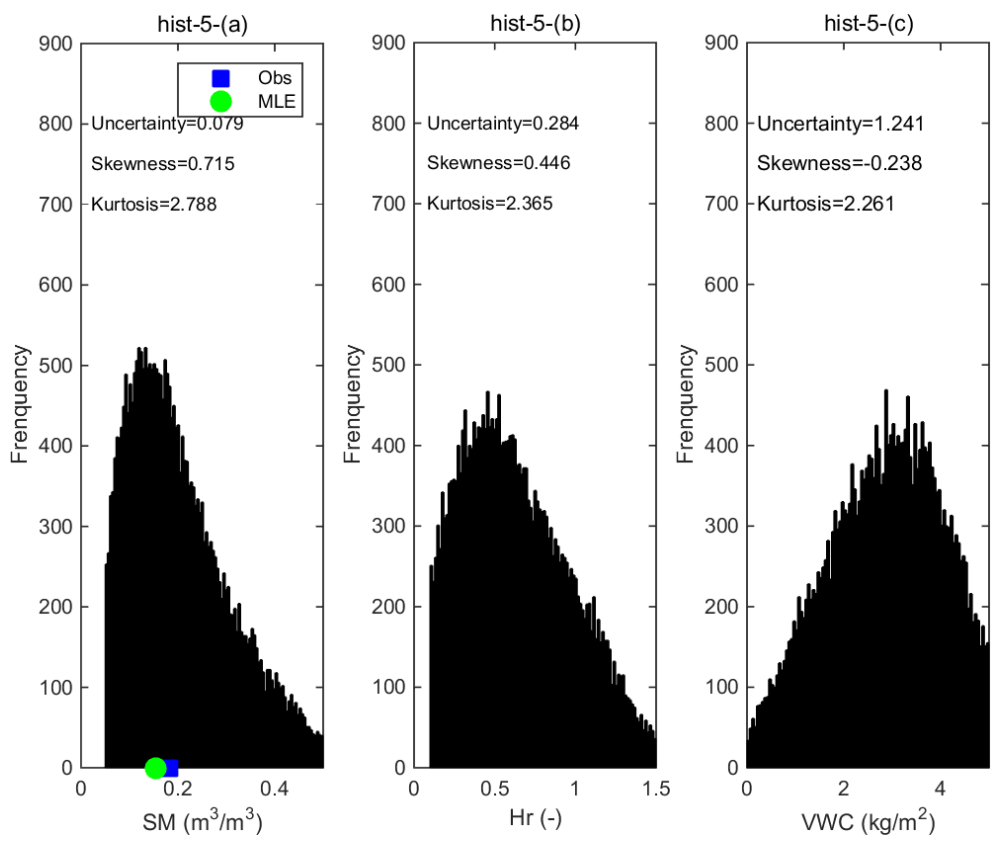

Fig. 2 The probability distribution of 3P retrieval objectives
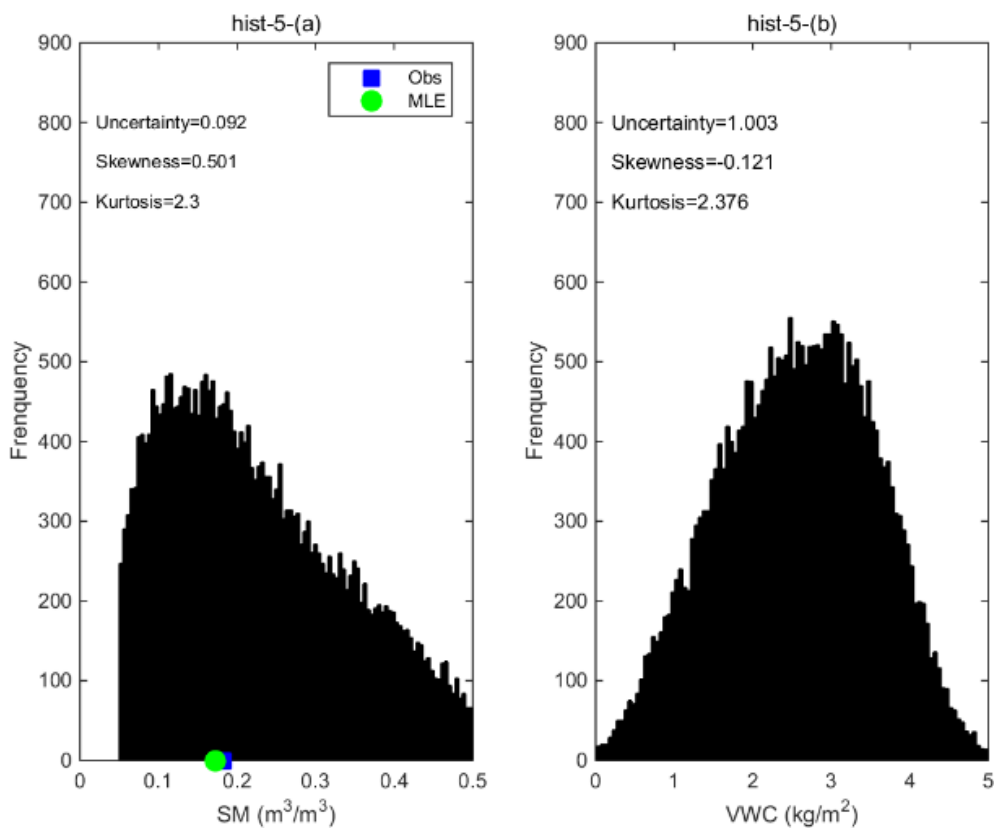

Fig. 3 The probability distribution of 2P_TB retrieval objectives 
Hydrol. Earth Syst. Sci. Discuss., doi:10.5194/hess-2017-34, 2017

Manuscript under review for journal Hydrol. Earth Syst. Sci.

Discussion started: 13 February 2017
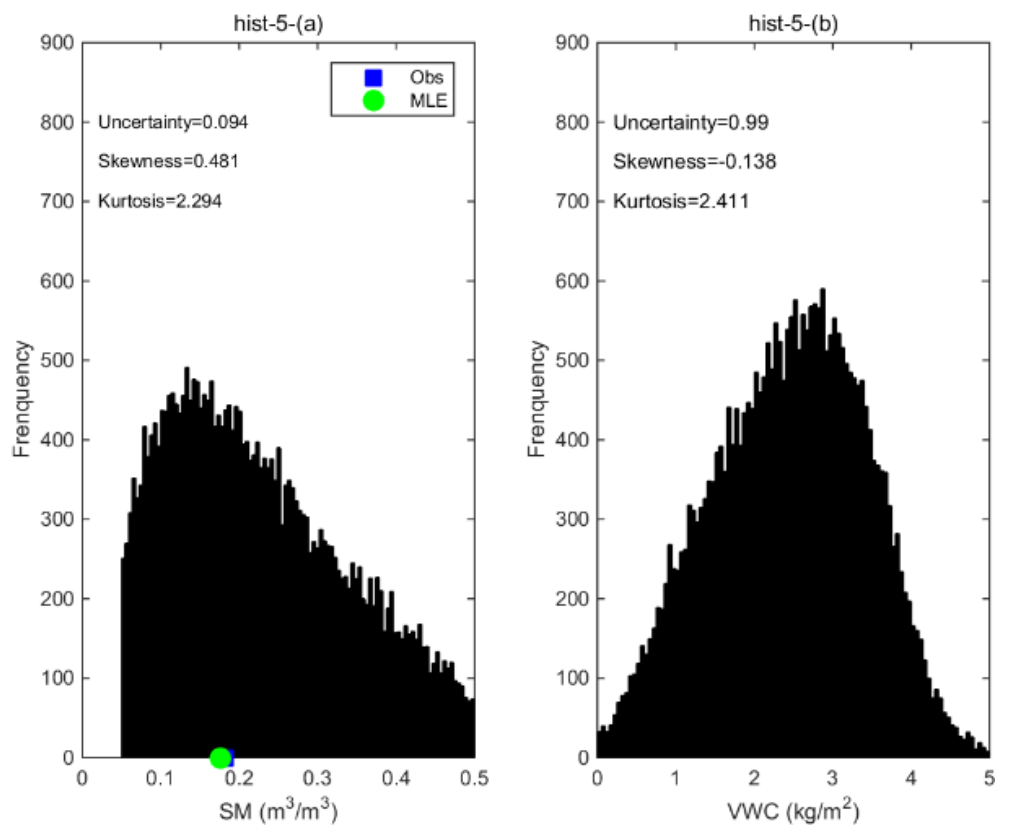

Fig. 4 The probability distribution of 2P_TBE retrieval objectives

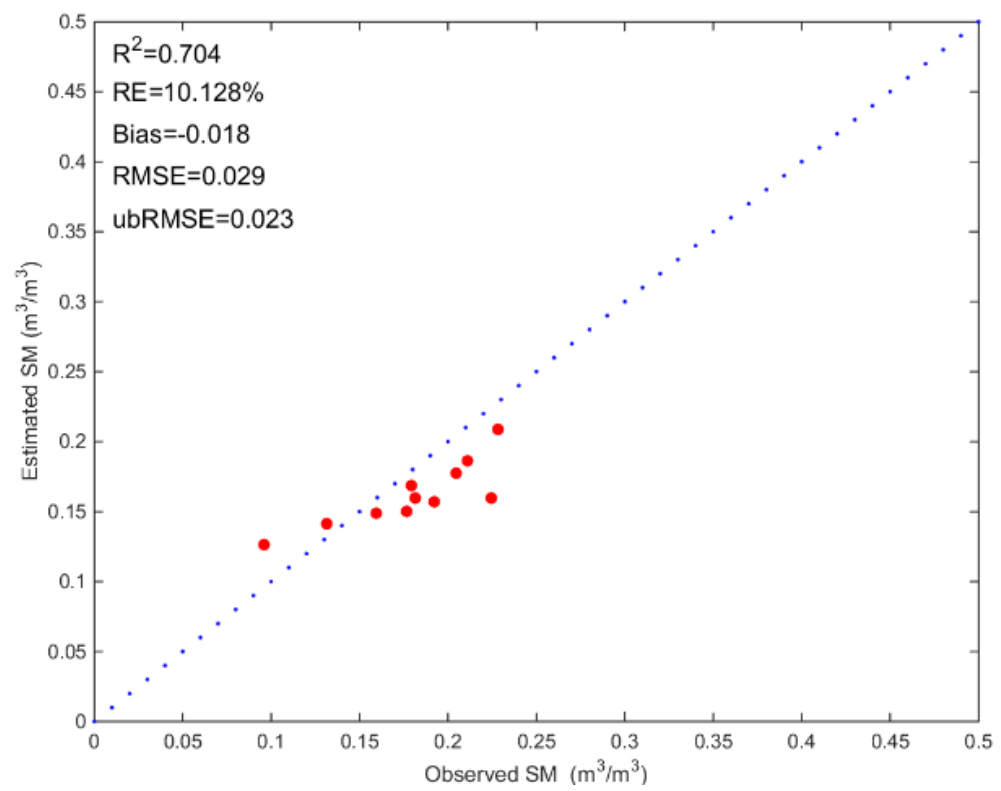

Fig. 5 The comparison of 3P strategy estimated and ground measured SM. 
Hydrol. Earth Syst. Sci. Discuss., doi:10.5194/hess-2017-34, 2017

Manuscript under review for journal Hydrol. Earth Syst. Sci.

Discussion started: 13 February 2017

(c) Author(s) 2017. CC-BY 3.0 License.

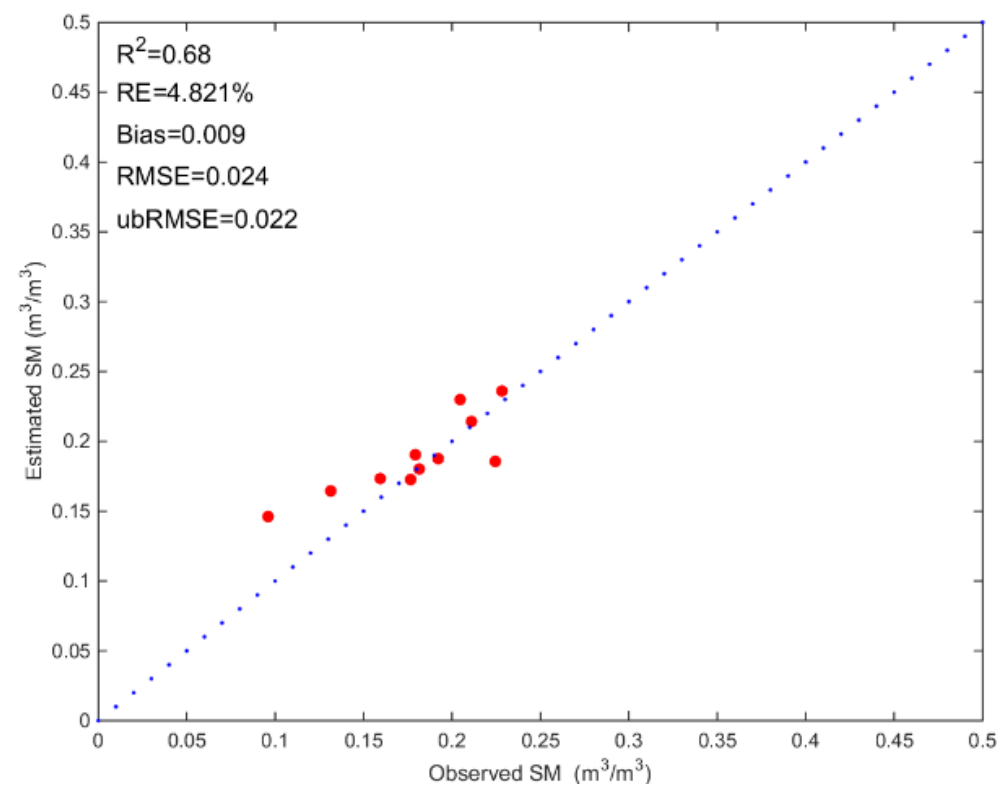

Fig. 6 The comparison of 2P_TB strategy estimated and ground measured SM.

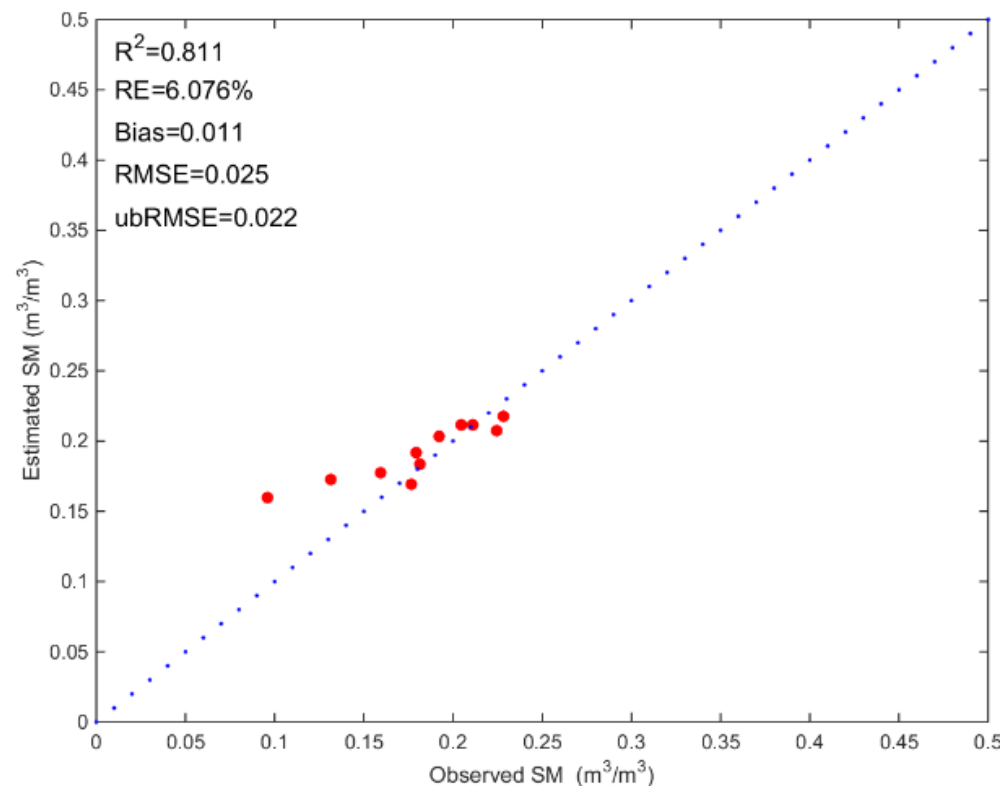

Fig. 7 The comparison of 2P_TBE strategy estimated and ground measured SM. 
Hydrol. Earth Syst. Sci. Discuss., doi:10.5194/hess-2017-34, 2017

Manuscript under review for journal Hydrol. Earth Syst. Sci.

Discussion started: 13 February 2017

(c) Author(s) 2017. CC-BY 3.0 License.
Hydrology and

Earth System

Sciences

Discussions

(c)
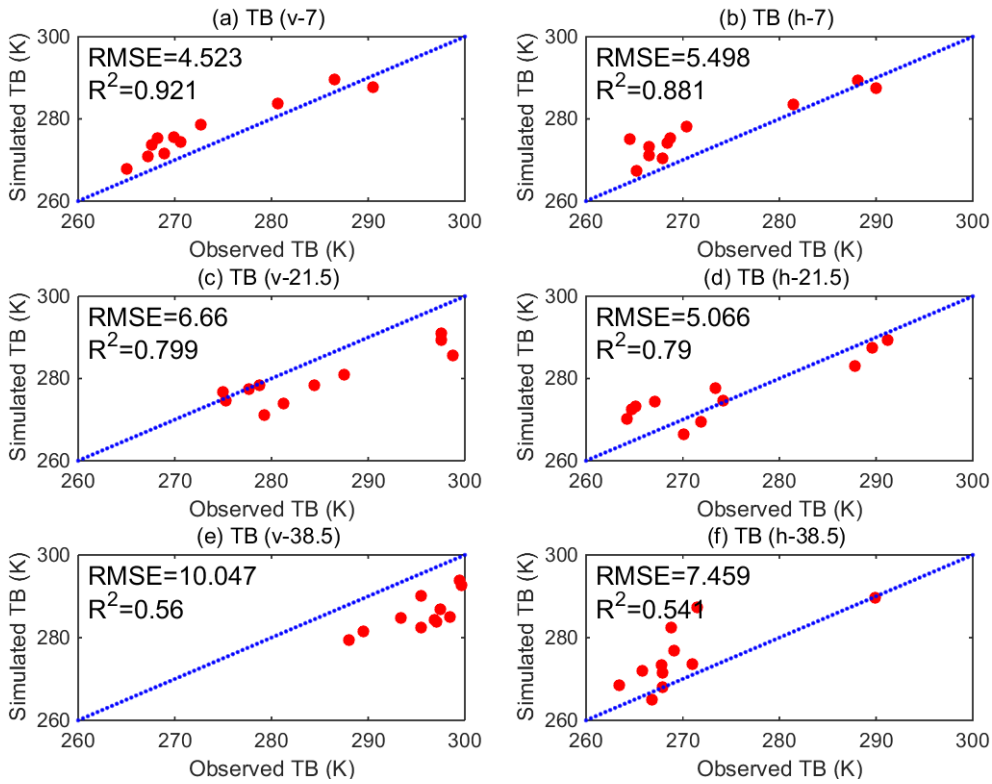

Fig.8. The comparison of PLMR observed TB with those simulated by MLE variables under 3P strategy.

(a) TB (v-7)

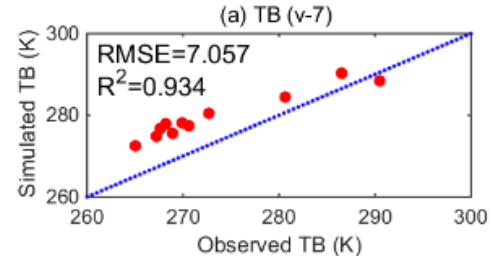

(c) TB (v-21.5)

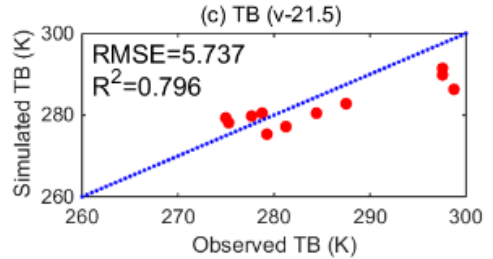

(e) TB (v-38.5)

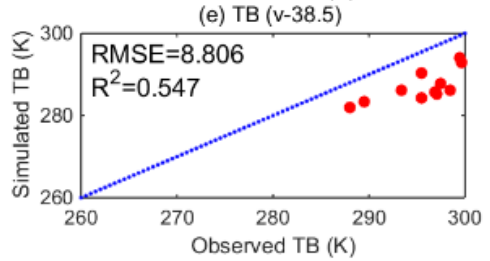

(b) TB (h-7)

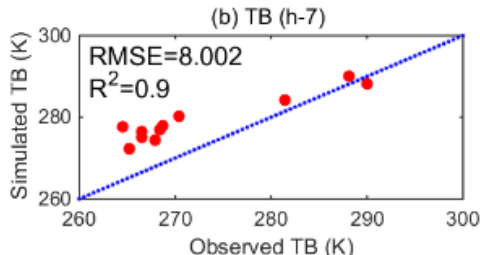

(d) TB (h-21.5)

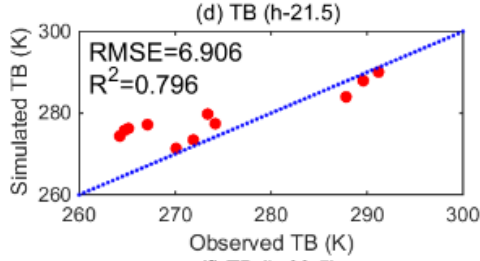

(f) TB (h-38.5)

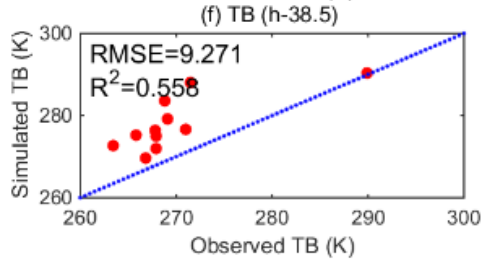

Fig.9. The comparison of PLMR observed TB with those simulated by MLE variables under 2P_TB strategy. 
Hydrol. Earth Syst. Sci. Discuss., doi:10.5194/hess-2017-34, 2017

Manuscript under review for journal Hydrol. Earth Syst. Sci.

Discussion started: 13 February 2017

(c) Author(s) 2017. CC-BY 3.0 License.
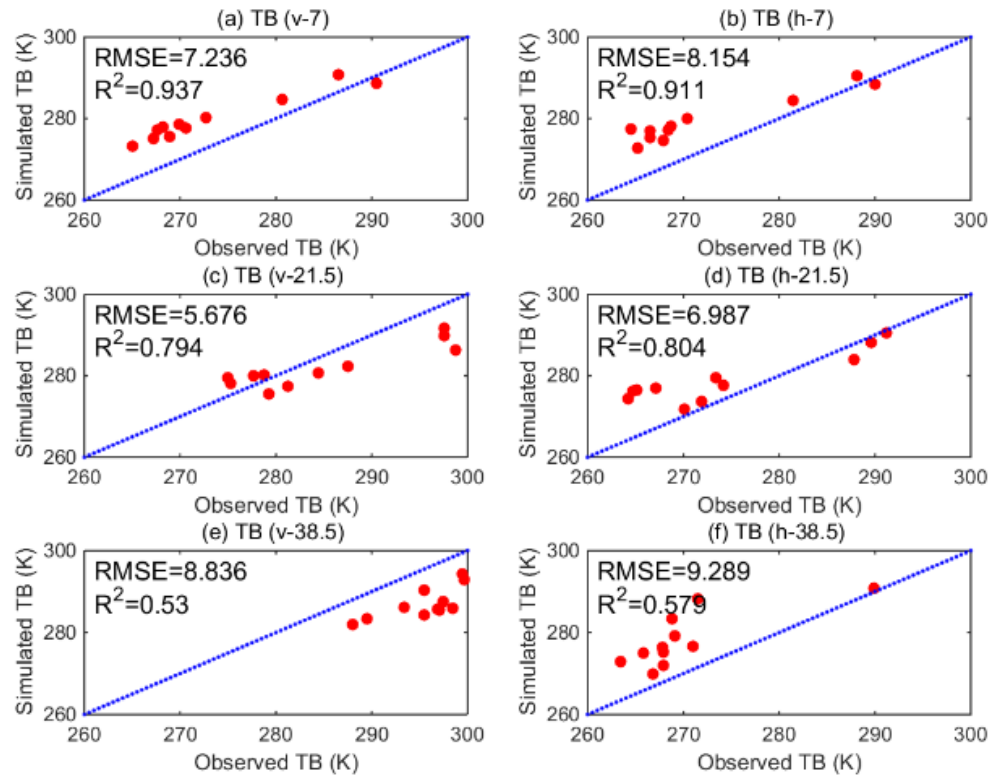

Fig.10. The comparison of PLMR observed TB with those simulated by MLE variables under 2P_TBE strategy. 